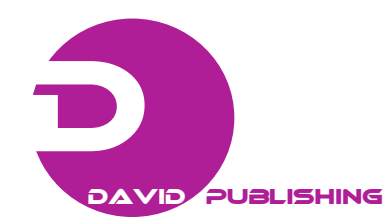

\title{
Problems in Planting That Significantly Affect the Quality and Safety of Fruits and Vegetables in Vietnam
}

\author{
Dam Sao Mai* and Trinh Xuan Ngo \\ Institute of Biotechnology and Food Technology, Ho Chi Minh University of Industry, 12 Nguyen Van Bao Str., Ho Chi Minh City, \\ Vietnam \\ *Corresponding author’s e-mail: damsaomai@yahoo.com
}

\begin{abstract}
At present, in Vietnam vegetables cultivation is done by the two modes: self-sufficiency and goods production. The second mode is applied in the areas: mono-cultivating, multi-cultivating and high-tech vegetables cultivation. In Vietnam there is nearly the half of the fruit and vegetable growers use fertilizer, purchased seed, or pesticides, though the proportion varies by commodity, region, and expenditure category. Among vegetable farmers, 34\% buy vegetable seed, $47 \%$ use fertilizer on their vegetables, and $22 \%$ report using pesticides to their vegetables. Pesticide used on vegetables is more common in all of Vietnam. All traders in Southern Vietnam used storage during the past year, while only about $69 \%$ of traders in the North used storage facilities. Few traders have chilled or frozen storage facilities. Just less than $3 \%$ of traders have refrigerated storage. These are mainly exporters in Southern Vietnam. In recent years, much food poisoning happened in Vietnam, because of pesticides in vegetable and fruit. So we need the projects to do the survey and to train the farmer for modern cultivation of vegetables, which is underway like the high quality vegetables. It is also necessary to have the production management, trademark, and distribution network.
\end{abstract}

Key words: Vegetables, fruits, cultivation, food safety, farmer. 